\title{
Why clinical trial outcomes fail to translate into benefits for patients
}

\author{
Carl Heneghan* (D), Ben Goldacre and Kamal R. Mahtani
}

\begin{abstract}
Clinical research should ultimately improve patient care. For this to be possible, trials must evaluate outcomes that genuinely reflect real-world settings and concerns. However, many trials continue to measure and report outcomes that fall short of this clear requirement. We highlight problems with trial outcomes that make evidence difficult or impossible to interpret and that undermine the translation of research into practice and policy. These complex issues include the use of surrogate, composite and subjective endpoints; a failure to take account of patients' perspectives when designing research outcomes; publication and other outcome reporting biases, including the under-reporting of adverse events; the reporting of relative measures at the expense of more informative absolute outcomes; misleading reporting; multiplicity of outcomes; and a lack of core outcome sets. Trial outcomes can be developed with patients in mind, however, and can be reported completely, transparently and competently. Clinicians, patients, researchers and those who pay for health services are entitled to demand reliable evidence demonstrating whether interventions improve patient-relevant clinical outcomes.
\end{abstract}

Keywords: Clinical outcomes, Surrogate outcomes, Composite outcomes, Publication bias, Reporting bias, Core outcome sets

\section{Background}

Clinical trials are the most rigorous way of testing how novel treatments compare with existing treatments for a given outcome. Well-conducted clinical trials have the potential to make a significant impact on patient care and therefore should be designed and conducted to achieve this goal. One way to do this is to ensure that trial outcomes are relevant, appropriate and of importance to patients in real-world clinical settings. However, relatively few trials make a meaningful contribution to patient care, often as a result of the way that the trial outcomes are chosen, collected and reported. For example, authors of a recent analysis of cancer drugs approved by the U.S. Food and Drug Administration (FDA) reported a lack of clinically meaningful benefit in many post-marketing studies, owing to the use of surrogates, which undermines the ability of physicians and patients to make informed treatment decisions [1].

\footnotetext{
* Correspondence: carl.heneghan@phc.ox.ac.uk
Centre for Evidence-Based Medicine, Nuffield Department of Primary Care

* Correspondence: carl.heneghan@phc.ox.ac.uk
Centre for Evidence-Based Medicine, Nuffield Department of Primary Care

Health Science, University of Oxford, Radcliffe Observatory Quarter,

Woodstock Road, Oxford OX2 6GG, UK
}

(c) The Author(s). 2017 Open Access This article is distributed under the terms of the Creative Commons Attribution 4.0 International License (http://creativecommons.org/licenses/by/4.0/), which permits unrestricted use, distribution, and reproduction in any medium, provided you give appropriate credit to the original author(s) and the source, provide a link to the Creative Commons license, and indicate if changes were made. The Creative Commons Public Domain Dedication waiver (http://creativecommons.org/publicdomain/zero/1.0/) applies to the data made available in this article, unless otherwise stated. outcomes are to clinical decision making. The World Health Organisation (WHO) recognises that 'choosing the most important outcome is critical to producing a useful guideline' [2]. A survey of 48 U.K. clinical trials units found that 'choosing appropriate outcomes to measure' as one of the top three priorities for methods research [3]. Yet, despite the importance of carefully selected trial outcomes to clinical practice, relatively little is understood about the components of outcomes that are critical to decision making.

Most articles on trial outcomes focus on one or two aspects of their development or reporting. Assessing the extent to which outcomes are critical, however, requires a comprehensive understanding of all the shortcomings that can undermine their validity (Fig. 1). The problems we set out are complex, often coexist and can interact, contributing to a situation where clinical trial outcomes commonly fail to translate into clinical benefits for patients. 


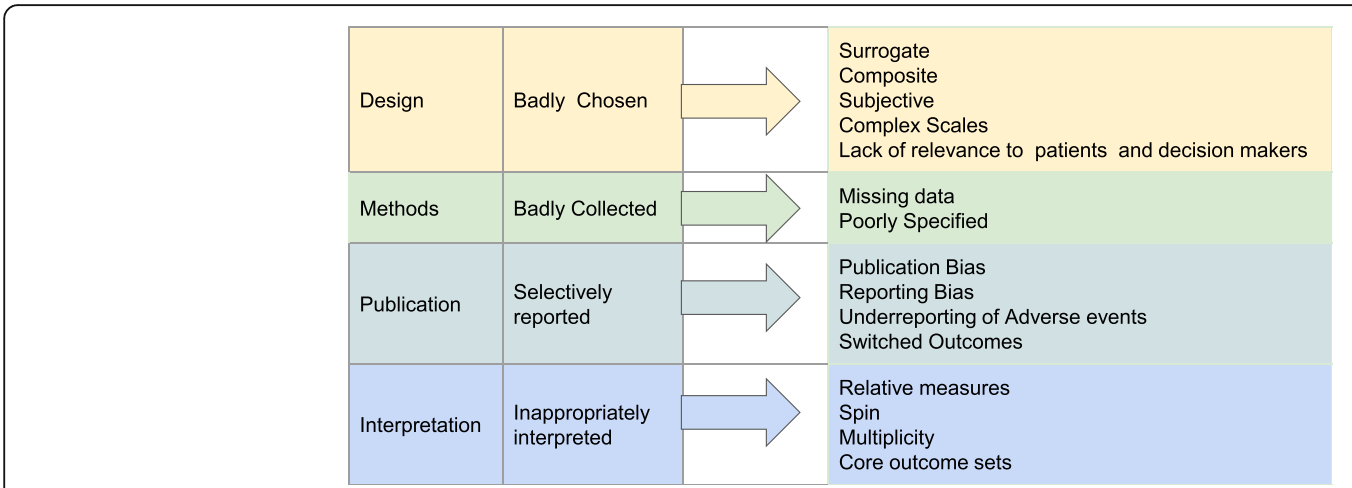

Fig. 1 Why clinical trial outcomes fail to translate into benefits for patients

\section{Main text}

\section{Badly chosen outcomes}

\section{Surrogate outcomes}

Surrogate markers are often used to infer or predict a more direct patient-oriented outcome, such as death or functional capacity. Such outcomes are popular because they are often cheaper to measure and because changes may emerge faster than the real clinical outcome of interest. This can be a valid approach when the surrogate marker has a strong association with the real outcome of interest. For example, intra-ocular pressure in glaucoma and blood pressure in cardiovascular disease are well-established markers. However, for many surrogates, such as glycated haemoglobin, bone mineral density and prostate-specific antigen, there are considerable doubts about their correlation with disease [4]. Caution is therefore required in their interpretation [5]. Authors of an analysis of 626 randomised controlled trials (RCTs) reported that $17 \%$ of trials used a surrogate primary outcome, but only one-third discussed their validity [6]. Surrogates generally provide less direct relevant evidence than studies using patient-relevant outcomes $[5,7]$, and over-interpretation runs the risk of incorrect interpretations because changes may not reflect important changes in outcomes [8]. As an example, researchers in a well-conducted clinical trial of the diabetes drug rosiglitazone reported that it effectively lowered blood glucose (a surrogate) [9]; however, the drug was subsequently withdrawn in the European Union because of increased cardiovascular events, the patient-relevant outcome [10].

\section{Composite outcomes}

The use of combination measures is highly prevalent in, for example, cardiovascular research. However, their use can often lead to exaggerated estimates of treatment effects or render a trial report uninterpretable. Authors of an analysis of 242 cardiovascular RCTs, published in six high-impact medical journals, found that in $47 \%$ of the trials, researchers reported a composite outcome [11]. Authors of a further review of 40 trials, published in 2008, found that composites often had little justification for their choice [12], were inconsistently defined, and often the outcome combinations did not make clinical sense [13]. Individual outcomes within a composite can vary in the severity of their effects, which may be misleading when the most important outcomes, such as death, make relatively little contribution to the overall outcome measure [14]. Having more event data by using a composite does allow more precise outcome estimation. Interpretation, however, is particularly problematic when data are missing. Authors of an analysis of 51 rheumatoid arthritis RCTs reported $>20 \%$ data was missing for the composite primary outcomes in 39\% of the trials [15]. Missing data often requires imputation; however, the optimal method to address this remains unknown [15].

\section{Subjective outcomes}

Where an observer exercises judgment while assessing an event, or where the outcome is self-reported, the outcome is considered subjective [16]. In trials with such outcomes, effects are often exaggerated, particularly when methodological biases occur (i.e., when outcome assessors are not blinded) $[17,18]$. In a systematic review of observer bias, non-blinded outcome assessors exaggerated ORs in RCTs by $36 \%$ compared with blinded assessors [19]. In addition, trials with inadequate or unclear sequence generation also biased estimates when outcomes were subjective [20]. Yet, despite these shortcomings, subjective outcomes are highly prevalent in trials as well as systematic reviews: In a study of 43 systematic reviews of drug interventions, researchers reported the primary outcome was objective in only $38 \%$ of the pooled analyses [21].

\section{Complex scales}

Combinations of symptoms and signs can be used to form outcome scales, which can also prove to be problematic. A 
review of 300 trials from the Cochrane Schizophrenia Group's register revealed that trials were more likely to be positive when unpublished and unreliable and nonvalidated scales were used [22]. Furthermore, changes to the measurement scale used during the trial (a form of outcome switching) was one of the possible causes for the high number of results favouring new rheumatoid arthritis drugs [23]. Clinical trials require rating scales that are rigorous, but this is difficult to achieve [24]. Moreover, patients want to know the extent to which they are free of a symptom or a sign, more so than the mean change in a score.

\section{Lack of relevance to patients and decision makers}

Interpretation of changes in trial outcomes needs to go beyond a simple discussion of statistical significance to include clinical significance. Sometimes, however, such interpretation does not happen: In a review of 57 dementia drug trials, researchers found that less than half (46\%) discussed the clinical significance of their results [17]. Furthermore, authors of a systematic assessment of the prevalence of patient-reported outcomes in cardiovascular trials published in the ten leading medical journals found that important outcomes for patients, such as death, were reported in only $23 \%$ of the 413 included trials. In $40 \%$ of the trials, patient-reported outcomes were judged to be of little added value, and $70 \%$ of the trials were missing crucial outcome data relevant to clinical decision making (mainly due to use of composite outcomes and under-reporting of adverse events) [25]. There has been some improvement over time in reporting of patient-relevant outcomes such as quality of life, but the situation remains dire: by 2010 , only $16 \%$ of cardiovascular disease trials reported quality of life, a threefold increase from 1997. Use of surrogate, composite and subjective outcomes further undermines relevance to patients [26] and often accompanies problems with reporting and interpretation [25].

Studies often undermine decision making by failing to determine thresholds of practical importance to patient care. The smallest difference a patient, or the patient's clinician, would be willing to accept to use a new intervention is the minimal clinically important difference (MCID). Crucially, clinicians and patients can assist in developing MCIDs; however, to date, such joint working is rare, and use of MCIDs has remained limited [27].

Problems are further compounded by the lack of consistency in the application of subjective outcomes across different interventions. Guidelines, for example, reject the use of antibiotics in sore throat [28] owing to their minimal effects on symptoms; yet, similar guidelines approve the use of antivirals because of their effects on symptoms [29], despite similar limited effects [30]. This contradiction occurs because decision makers, and particularly guideline developers, frequently lack understanding of the MCIDs required to change therapeutic decision making. Caution is also warranted, though, when it comes to assessing minimal effects: Authors of an analysis of 51 trials found small outcome effects were commonly reported and often eliminated by the presence of minimal bias [31]. Also, MCIDs may not necessarily reflect what patients consider to be important for decision making. Researchers in a study of patients with rheumatoid arthritis reported that the difference they considered really important was up to three to four times greater than MCIDs [32]. Moreover, inadequate duration of follow-up and trials that are stopped too early also contribute to a lack of reliable evidence for decision makers. For example, authors of systematic reviews of patients with mild depression have reported that only a handful of trials in primary care provide outcome data on the long-term effectiveness (beyond 12 weeks) of anti-depressant drug treatments [33]. Furthermore, results of simulation studies show that trials halted too early, with modest effects and few events, will result in large overestimates of the outcome effect [34].

\section{Badly collected outcomes Missing data}

Problems with missing data occur in almost all research: Its presence reduces study power and can easily lead to false conclusions. Authors of a systematic review of 235 RCTs found that $19 \%$ of the trials were no longer significant, based on assumptions that the losses to follow-up actually had the outcome of interest. This figure was $58 \%$ in a worst-case scenario, where all participants lost to follow-up in the intervention group and none in the control group had the event of interest [35]. The ' 5 and 20 rule' (i.e., if $>20 \%$ missing data, then the study is highly biased; if $<5 \%$, then low risk of bias) exists to aid understanding. However, interpretation of the outcomes is seriously problematic when the absolute effect size is less than the loss to follow-up. Despite the development of a number of different ways of handling missing data, the only real solution is to prevent it from happening in the first place [36].

\section{Poorly specified outcomes}

It is important to determine the exact definitions for trial outcomes because poorly specified outcomes can lead to confusion. As an example, in a Cochrane review on neuraminidase inhibitors for preventing and treating influenza, the diagnostic criteria for pneumonia could be either (1) laboratory-confirmed diagnosis (e.g., based on radiological evidence of infection); (2) clinical diagnosis by a doctor without laboratory confirmation; or (3) another type of diagnosis, such as self-report by the patient. Treatment effects for pneumonia were statistically different, depending on which diagnostic criteria 
were used. Furthermore, who actually assesses the outcome is important. Self-report measures are particularly prone to bias, owing to their subjectivity, but even the type of clinician assessing the outcome can affect the estimate: Stroke risk because of carotid endarterectomy differs depending on whether patients are assessed by a neurologist or a surgeon [37].

\section{Selectively reported outcomes Publication bias}

Problems with publication bias are well documented. Among cohort studies following registered or ethically approved trials, half go unpublished [38], and trials with positive outcomes are twice as likely to be published, and published faster, compared with trials with negative outcomes $[39,40]$. The International Committee of Medical Journal Editors have stated the importance of trial registration to address the issue of publication bias [41]. Their policy requires investigators to deposit information about trial design into an accepted clinical trials registry before the onset of patient enrolment'. Despite this initiative, publication bias remains a major issue contributing to translational failure. This led to the AllTrials campaign, which calls for all past and present clinical trials to be registered and their results reported [42].

\section{Reporting bias}

Outcome reporting bias occurs when a study has been published, but some of the outcomes measured and analysed have not been reported. Reporting bias is an under-recognised problem that significantly affects the validity of the outcome. Authors of a review of 283 Cochrane reviews found that more than half did not include data on the primary outcome [43]. One manifestation of reporting bias is the under-reporting of adverse events.

\section{Under-reporting of adverse events}

Interpreting the net benefits of treatments requires full outcome reporting of both the benefits and the harms in an unbiased manner. A review of recombinant human bone morphogenetic protein 2 used in spinal fusion, however, showed that data from publications substantially underestimated adverse events when compared with individual participant data or internal industry reports [44]. A further review of 11 studies comparing adverse events in published and unpublished documents reported that $43 \%$ to $100 \%$ (median $64 \%$ ) of adverse events (including outcomes such as death or suicide) were missed when journal publications were solely relied on [45]. Researchers in multiple studies have found that journal publications under-report side effects and therefore exaggerate treatment benefits when compared with more complete information presented in clinical study reports [46], FDA reviews [47], ClinicalTrials.gov study reports [48] and reports obtained through litigation [49].

The aim of the Consolidated Standards of Reporting Trials (CONSORT), currently endorsed by 585 medical journals, is to improve reporting standards. However, despite CONSORT's attempts, both publication and reporting bias remain a substantial problem. This impacts substantially the results of systematic reviews. Authors of an analysis of 322 systematic reviews found that $79 \%$ did not include the full data on the main harm outcome. This was due mainly to poor reporting in the included primary studies; in nearly two-thirds of the primary studies, outcome reporting bias was suspected [50]. The aim of updates to the Preferred Reporting Items for Systematic Reviews and Meta-Analyses (PRISMA) checklist for systematic reviews is to improve the current situation by ensuring that a minimal set of adverse events items is reported [51].

Switched outcomes is the failure to correctly report prespecified outcomes, which remains highly prevalent and presents significant problems in interpreting results [52]. Authors of a systematic review of selective outcome reporting, including 27 analyses, found that the median proportion of trials with a discrepancy between the registered and published primary outcome was 31\% [53]. Researchers in a recent study of 311 manuscripts submitted to The BMJ found that $23 \%$ of outcomes pre-specified in the protocol went unreported [54]. Furthermore, many trial authors and editors seem unaware of the ramifications of incorrect outcome reporting. The Centre for Evidence-Based Medicine Outcome Monitoring Project (COMPare) prospectively monitored all trials in five journals and submitted correction letters in real time on all misreported trials, but the majority of correction letters submitted were rejected by journal editors [55].

\section{Inappropriately interpreted outcomes Relative measures}

Relative measures can exaggerate findings of modest clinical benefit and can often be uninterpretable, such as if control event rates are not reported. Authors of a 2009 review of 344 journal articles reporting on health inequalities research found that, of the $40 \%$ of abstracts reporting an effect measure, $88 \%$ reported only the relative measure, $9 \%$ an absolute measure and just $2 \%$ reported both [56]. In contrast, $75 \%$ of all full-text articles reported relative effects, and only $7 \%$ reported both absolute and relative measures in the full text, despite reporting guidelines, such as CONSORT, recommending using both measures whenever possible [57].

\section{Spin}

Misleading reporting by presenting a study in a more positive way than the actual results reflect constitutes 
'spin' [58]. Authors of an analysis of 72 trials with nonsignificant results reported it was a common phenomenon, with $40 \%$ of the trials containing some form of spin. Strategies included reporting on statistically significant results for within-group comparisons, secondary outcomes, or subgroup analyses and not the primary outcome, or focussing the reader on another study objective away from the statistically nonsignificant result [59]. Additionally, the results revealed the common occurrence of spin in the abstract, the most accessible and most read part of a trial report. In a study that randomised 300 clinicians to two versions of the same abstract (the original with spin and a rewritten version without spin), researchers found there was no difference in clinicians' rating of the importance of the study or the need for a further trial [60]. Spin is also often found in systematic reviews; authors of an analysis found that spin was present in $28 \%$ of the 95 included reviews of psychological therapies [61]. A consensus process amongst members of the Cochrane Collaboration has identified 39 different types of spin, 13 of which were specific to systematic reviews. Of these, the three most serious were recommendations for practice not supported by findings in the conclusion, misleading titles and selective reporting [62].

\section{Multiplicity}

Appropriate attention has to be paid to the multiplicity of outcomes that are present in nearly all clinical trials. The higher the number of outcomes, the more chance there is of false-positive results and unsubstantiated claims of effectiveness [63]. The problem is compounded when trials have multiple time points, further increasing the number of outcomes. For licensing applications, secondary outcomes are considered insufficiently convincing to establish the main body of evidence and are intended to provide supporting evidence in relation to the primary outcome [63]. Furthermore, about half of all trials make further claims by undertaking subgroup analysis, but caution is warranted when interpreting their effects. An analysis of 207 studies found that 31\% claimed a subgroup effect for the primary outcome; yet, such subgroups were often not pre-specified (a form of outcome switching) and frequently formed part of a large number of subgroup analyses [64]. At a minimum, triallists should perform a test of interaction, and journals should ensure it is done, to examine whether treatment effects actually differ amongst subpopulations [64], and decision makers should be very wary of high numbers of outcomes included in a trial report.

\section{Core outcome sets}

Core outcome sets could facilitate comparative effectiveness research and evidence synthesis. As an example, all of the top-cited Cochrane reviews in 2009 described problems with inconsistencies in their reported outcomes [65]. Standardised core outcome sets take account of patient preferences that should be measured and reported in all trials for a specific therapeutic area [65]. Since 1992, the Outcome Measures in Rheumatoid Arthritis Clinical Trials (OMERACT) collaboration has advocated the use of core outcome sets [66], and the Core Outcome Measures in Effectiveness Trials (COMET) Initiative collates relevant resources to facilitate core outcome development and user engagement [67, 68]. Consequently, their use is on the increase, and the Grading of Recommendations Assessment, Development and Evaluation (GRADE) working group recommend up to seven patient-important outcomes be listed in the 'summary of findings' tables in systematic reviews [69].

\section{Conclusions}

The treatment choices of patients and clinicians should ideally be informed by evidence that interventions improve patient-relevant outcomes. Too often, medical research falls short of this modest ideal. However, there are ways forward. One of these is to ensure that trials are conceived and designed with greater input from end users, such as patients. The James Lind Alliance (JLA) brings together clinicians, patients and carers to identify areas of practice where uncertainties exist and to prioritise clinical research questions to answer them. The aim of such 'priority setting partnerships' (PSPs) is to develop research questions using measurable outcomes of direct relevance to patients. For example, a JLA PSP of dementia research generated a list of key measures, including quality of life, independence, management of behaviour and effect on progression of disease, as outcomes that were relevant to both persons with dementia and their carers [70].

However, identifying best practice is only the beginning of a wider process to change the culture of research. The ecosystem of evidence-based medicine is broad, including ethics committees, sponsors, regulators, triallists, reviewers and journal editors. All these stakeholders need to ensure that trial outcomes are developed with patients in mind, that unbiased methods are adhered to, and that results are reported in full and in line with those pre-specified at the trial outset. Until addressed, the problems of how outcomes are chosen, collected, reported and subsequently interpreted will continue to make a significant contribution to the reasons why clinical trial outcomes often fail to translate into clinical benefit for patients.

Abbreviations

COMET: Core Outcome Measures in Effectiveness Trials; COMPare: Centre for Evidence-Based Medicine Outcome Monitoring Project;

CONSORT: Consolidated Standards of Reporting Trials; FDA: Food and Drug 
Administration; GRADE: Grading of Recommendations Assessment, Development and Evaluation; JLA: James Lind Alliance; MCID: Minimal clinically important difference; OMERACT: Outcome Measures in Rheumatoid Arthritis Clinical Trials; PRISMA: Preferred Reporting Items for Systematic Reviews and Meta-Analyses; PSP: Priority setting partnership; RCT: Randomised controlled trial; WHO: World Health Organisation

\section{Acknowledgements}

Not applicable.

\section{Funding}

No specific funding.

\section{Availability of data and materials}

Not applicable.

\section{Authors' contributions}

$\mathrm{CH}, \mathrm{BG}$ and KRM equally participated in the design and coordination of this commentary and helped to draft the manuscript. All authors read and approved the final manuscript

\section{Authors' information}

All authors work at the Centre for Evidence-Based Medicine at the Nuffield Department of Primary Care Health Sciences, University of Oxford, Oxford,

\section{Competing interests}

BG has received research funding from the Laura and John Arnold Foundation, the Wellcome Trust, the NHS National Institute for Health Research, the Health Foundation, and the WHO. He also receives personal income from speaking and writing for lay audiences on the misuse of science. KRM has received funding from the NHS National Institute for Health Research and the Royal College of General Practitioners for independent research projects. $\mathrm{CH}$ has received grant funding from the $\mathrm{WHO}$, the NIHR and the NIHR School of Primary Care. He is also an advisor to the WHO International Clinical Trials Registry Platform (ICTRP). BG and CH are founders of the AllTrials campaign. The views expressed are those of the authors and not necessarily those of any of the funders or institutions mentioned above.

\section{Consent for publication}

Not applicable.

\section{Ethics approval and consent to participate}

Not applicable.

\section{Received: 13 October 2016 Accepted: 28 February 2017} Published online: 14 March 2017

\section{References}

1. Rupp T, Zuckerman D. Quality of life, overall survival, and costs of cancer drugs approved based on surrogate endpoints. JAMA Intern Med. 2017;177: 276-7. doi:10.1001/jamainternmed.2016.7761.

2. World Health Organisation (WHO). WHO handbook for guideline developers. Geneva: WHO; 2012. http://apps.who.int/iris/bitstream/10665/ 75146/1/9789241548441_eng.pdf?ua=1. Accessed 11 Mar 2017.

3. Tudur Smith C, Hickey H, Clarke M, Blazeby J, Williamson P. The trials methodological research agenda: results from a priority setting exercise. Trials. 2014;15:32. doi:10.1186/1745-6215-15-32.

4. Twaddell S. Surrogate outcome markers in research and clinical practice. Aust Prescr. 2009;32:47-50. doi:10.18773/austprescr.2009.023.

5. Yudkin JS, Lipska KJ, Montori VM. The idolatry of the surrogate. BMJ. 2011; 343:d7995. doi:10.1136/bmj.d7995.

6. la Cour JL, Brok J, Gøtzsche PC. Inconsistent reporting of surrogate outcomes in randomised clinical trials: cohort study. BMJ. 2010;341:c3653. doi:10.1136/bmj.c3653

7. Atkins D, Briss PA, Eccles M, Flottorp S, Guyatt GH, Harbour RT, et al. Systems for grading the quality of evidence and the strength of recommendations II: pilot study of a new system. BMC Health Serv Res. 2005;5:25. doi:10.1186/1472-6963-5-25

8. D'Agostino Jr RB. Debate: the slippery slope of surrogate outcomes. Curr Control Trials Cardiovasc Med. 2000;1:76-8. doi:10.1186/cvm-1-2-076.
9. DREAM (Diabetes REduction Assessment with ramipril and rosiglitazone Medication) Trial Investigators. Effect of rosiglitazone on the frequency of diabetes in patients with impaired glucose tolerance or impaired fasting glucose: a randomised controlled trial. Lancet. 2006:368:1096-105. doi:10. 1016/S0140-6736(06)69420-8. A published erratum appears in Lancet. 2006;368:1770.

10. Cohen D. Rosiglitazone: what went wrong? BMJ. 2010;341:c4848. doi:10.1136/bmj.c4848

11. Ferreira-González I, Busse JW, Heels-Ansdell D, Montori VM, Akl EA, Bryant DM, et al. Problems with use of composite end points in cardiovascular trials: systematic review of randomised controlled trials. BMJ. 2007;334:786. doi:10.1136/bmj.39136.682083.AE

12. Freemantle N, Calvert MJ. Interpreting composite outcomes in trials. BMJ. 2010;341:c3529. doi:10.1136/bmj.c3529.

13. Cordoba G, Schwartz L, Woloshin S, Bae H, Gøtzsche PC. Definition, reporting, and interpretation of composite outcomes in clinical trials: systematic review. BMJ. 2010;341:c3920. doi:10.1136/bmj.c3920.

14. Lim E, Brown A, Helmy A, Mussa S, Altman DG. Composite outcomes in cardiovascular research: a survey of randomized trials. Ann Intern Med. 2008; 149:612-7.

15. Ibrahim F, Tom BDM, Scott DL, Prevost AT. A systematic review of randomised controlled trials in rheumatoid arthritis: the reporting and handling of missing data in composite outcomes. Trials. 2016;17:272. doi:10.1186/s13063-016-1402-5.

16. Moustgaard H, Bello S, Miller FG, Hróbjartsson A. Subjective and objective outcomes in randomized clinical trials: definitions differed in methods publications and were often absent from trial reports. J Clin Epidemiol. 2014;67:1327-34. doi:10.1016/j.jclinepi.2014.06.020.

17. Molnar FJ, Man-Son-Hing M, Fergusson D. Systematic review of measures of clinical significance employed in randomized controlled trials of drugs for dementia. J Am Geriatr Soc. 2009;57:536-46. doi:10.1111/j.1532-5415.2008.02122.x

18. Wood L, Egger M, Gluud LL, Schulz KF, Jüni $P$, Altman DG, et al. Empirical evidence of bias in treatment effect estimates in controlled trials with different interventions and outcomes: meta-epidemiological study. BMJ. 2008:336:601-5. doi:10.1136/bmj.39465.451748.AD

19. Hróbjartsson A, Thomsen ASS, Emanuelsson F, Tendal B, Hilden J, Boutron I, et al. Observer bias in randomised clinical trials with binary outcomes: systematic review of trials with both blinded and non-blinded outcome assessors. BMJ. 2012;344:e1119. doi:10.1136/bmj.e1119.

20. Page MJ, Higgins JPT, Clayton G, Sterne JA, Hróbjartsson A, Savović J. Empirical evidence of study design biases in randomized trials: systematic review of meta-epidemiological studies. PLoS One. 2016;11:e0159267. doi: 10.1371/journal.pone.0159267.

21. Abraha I, Cherubini A, Cozzolino F, De Florio R, Luchetta ML, Rimland JM, et al. Deviation from intention to treat analysis in randomised trials and treatment effect estimates: meta-epidemiological study. BMJ. 2015:350: h2445. doi:10.1136/bmj.h2445.

22. Marshall M, Lockwood A, Bradley C, Adams C, Joy C, Fenton M. Unpublished rating scales: a major source of bias in randomised controlled trials of treatments for schizophrenia. Br J Psychiatry. 2000;176:249-52. doi: 10.1192/bjp.176.3.249

23. Gøtzsche PC. Methodology and overt and hidden bias in reports of 196 doubleblind trials of nonsteroidal antiinflammatory drugs in rheumatoid arthritis. Control Clin Trials. 1989:10:31-56. https://www.ncbi.nlm.nih.gov/pubmed/2702836. A published erratum appears in Control Clin Trials. 1989;10:356.

24. Hobart JC, Cano SJ, Zajicek JP, Thompson AJ. Rating scales as outcome measures for clinical trials in neurology: problems, solutions, and recommendations. Lancet Neurol. 2007;6:1094-105. doi:10.1016/S1474-4422(07)70290-9. A published erratum appears in Lancet Neurol. 2008;7:25.

25. Rahimi K, Malhotra A, Banning AP, Jenkinson C. Outcome selection and role of patient reported outcomes in contemporary cardiovascular trials: systematic review. BMJ. 2010;341:c5707. doi:10.1136/bmj.c5707.

26. Rothwell PM. Factors that can affect the external validity of randomised controlled trials. PLoS Clin Trials. 2006;1:e9. doi:10.1371/journal.pctr.0010009.

27. Make B. How can we assess outcomes of clinical trials: the MCID approach. COPD. 2007:4:191-4

28. National Institute for Health and Care Excellence. https://cks.nice.org.uk sore-throat-acute\#!topicsummary. Accessed 11 Mar 2017.

29. National Institute for Health and Care Excellence (NICE). Amantadine, oseltamivir and zanamivir for the treatment of influenza: technology appraisal guidance. NICE guideline TA168. London: NICE; 2009. https://www.nice.org.uk/Guidance/ ta168. Accessed 28 Dec 2016. 
30. Heneghan CJ, Onakpoya I, Jones MA, Doshi P, Del Mar CB, Hama R, et al. Neuraminidase inhibitors for influenza: a systematic review and metaanalysis of regulatory and mortality data. Health Technol Assess. 2016;20: (42). doi:10.3310/hta20420.

31. Siontis GCM, loannidis JPA. Risk factors and interventions with statistically significant tiny effects. Int J Epidemiol. 2011:40:1292-307. doi:10.1093/ije/dyr099.

32. Wolfe F, Michaud K, Strand V. Expanding the definition of clinical differences: from minimally clinically important differences to really important differences: analyses in 8931 patients with rheumatoid arthritis. J Rheumatol. 2005;32:583-9.

33. Linde K, Kriston L, Rücker G, Jamil S, Schumann I, Meissner K, et al. Efficacy and acceptability of pharmacological treatments for depressive disorders in primary care: systematic review and network meta-analysis. Ann Fam Med. 2015;13:69-79. doi:10.1370/afm.1687.

34. Guyatt GH, Briel M, Glasziou P, Bassler D, Montori VM. Problems of stopping trials early. BMJ. 2012;344:e3863. doi:10.1136/bmj.e3863.

35. Akl EA, Briel M, You JJ, Sun X, Johnston BC, Busse JW, et al. Potential impact on estimated treatment effects of information lost to follow-up in randomised controlled trials (LOST-IT): systematic review. BMJ. 2012;344: e2809. doi:10.1136/bmj.e2809.

36. Kang $H$. The prevention and handling of the missing data. Korean J Anesthesiol. 2013;64:402-6. doi:10.4097/kjae.2013.64.5.402.

37. Rothwell P, Warlow C. Is self-audit reliable? Lancet. 1995;346:1623. doi:10. 1016/s0140-6736(95)91953-8.

38. Schmucker C, Schell LK, Portalupi S, Oeller P, Cabrera L, Bassler D, et al. Extent of non-publication in cohorts of studies approved by research ethics committees or included in trial registries. PLoS One. 2014;9:e114023. doi:10. 1371/journal.pone.0114023.

39. Song F, Parekh S, Hooper L, Loke YK, Ryder J, Sutton AJ, et al. Dissemination and publication of research findings: an updated review of related biases. Health Technol Assess. 2010;14(8). doi:10.3310/hta14080.

40. Hopewell S, Loudon K, Clarke MJ, Oxman AD, Dickersin K. Publication bias in clinical trials due to statistical significance or direction of trial results. Cochrane Database Syst Rev. 2009;1:MR000006. doi:10.1002/14651858. MR000006.pub3.

41. Laine C, De Angelis C, Delamothe T, Drazen JM, Frizelle FA, Haug C, et al. Clinical trial registration: looking back and moving ahead. Ann Intern Med. 2007:147:275-7. doi:10.7326/0003-4819-147-4-200708210-00166.

42. AllTrials. About AllTrials. http://www.alltrials.net/find-out-more/aboutalltrials/. Accessed 11 Mar 2017.

43. Kirkham JJ, Dwan KM, Altman DG, Gamble C, Dodd S, Smyth R, et al. The impact of outcome reporting bias in randomised controlled trials on a cohort of systematic reviews. BMJ. 2010;340:c365. doi:10.1136/bmj.c365.

44. Rodgers MA, Brown JVE, Heirs MK, Higgins JPT, Mannion RJ, Simmonds MC, et al. Reporting of industry funded study outcome data: comparison of confidential and published data on the safety and effectiveness of rhBMP-2 for spinal fusion. BMJ. 2013;346:f3981. doi:10.1136/bmj.f3981.

45. Golder S, Loke YK, Wright K, Norman G. Reporting of adverse events in published and unpublished studies of health care interventions: a systematic review. PLoS Med. 2016;13:e1002127. doi:10.1371/journal.pmed.1002127.

46. Wieseler B, Wolfram N, McGauran N, Kerekes MF, Vervölgyi V, Kohlepp P, et al. Completeness of reporting of patient-relevant clinical trial outcomes: comparison of unpublished clinical study reports with publicly available data. PLoS Med. 2013;10:e1001526. doi:10.1371/journal.pmed.1001526.

47. Hart B, Lundh A, Bero L. Effect of reporting bias on meta-analyses of drug trials: reanalysis of meta-analyses. BMJ. 2012;344:d7202. doi:10. 1136/bmj.d7202.

48. Schroll JB, Penninga El, Gøtzsche PC. Assessment of Adverse Events in Protocols, Clinical Study Reports, and Published Papers of Trials of Orlistat: A Document Analysis. PLoS Med. 2016;13(8):e1002101. doi:10.1371/journal. pmed.1002101.

49. Vedula SS, Bero L, Scherer RW, Dickersin K, et al. Outcome reporting in industry-sponsored trials of gabapentin for off-label use. N Engl J Med. 2009:361:1963-71. doi:10.1056/nejmsa0906126.

50. Saini P, Loke YK, Gamble C, Altman DG, Williamson PR, Kirkham JJ. Selective reporting bias of harm outcomes within studies: findings from a cohort of systematic reviews. BMJ. 2014;349:g6501. doi:10.1136/bmj.g6501.

51. Zorzela L, Loke YK, loannidis JP, Golder S, Santaguida P, Altman DG, et al. PRISMA harms checklist: improving harms reporting in systematic reviews. BMJ. 2016:352:1157 doi:10.1136/bmj.1157. A published erratum appears in BMJ. 2016;353:12229.
52. Smyth RMD, Kirkham JJ, Jacoby A, Altman DG, Gamble C, Williamson PR. Frequency and reasons for outcome reporting bias in clinical trials: interviews with trialists. BMJ. 2011;342:C7153. doi:10.1136/bmj.c7153.

53. Dwan K, Altman DG, Clarke M, Gamble C, Higgins JPT, Sterne JA, et al. Evidence for the selective reporting of analyses and discrepancies in clinical trials: a systematic review of cohort studies of clinical trials. PLoS Med. 2014; 11:e1001666. doi:10.1371/journal.pmed.1001666.

54. Weston J, Dwan K, Altman D, Clarke M, Gamble C, Schroter S, et al. Feasibility study to examine discrepancy rates in prespecified and reported outcomes in articles submitted to The BMJ. BMJ Open. 2016;6:e010075. doi: 10.1136/bmjopen-2015-010075.

55. Goldacre B, Drysdale H, Powell-Smith A, Dale A, Milosevic I, Slade E, et al. The COMPare Trials Project. 2016. http://compare-trials.org/. Accessed 11 Mar 2017.

56. King NB, Harper S, Young ME. Use of relative and absolute effect measures in reporting health inequalities: structured review. BMJ. 2012;345:e5774. doi: 10.1136/bmj.e5774.

57. Schulz KF, Altman DG, Moher D, CONSORT Group. CONSORT 2010 statement: updated guidelines for reporting parallel group randomised trials. BMJ. 2010;340:c332. doi:10.1136/bmj.c332.

58. Mahtani KR. 'Spin' in reports of clinical research. Evid Based Med. 2016;21: 201-2. doi:10.1136/ebmed-2016-110570.

59. Boutron I, Dutton S, Ravaud P, Altman DG. Reporting and interpretation of randomized controlled trials with statistically nonsignificant results for primary outcomes. JAMA. 2010:303:2058-64. doi:10.1001/jama.2010.651.

60. Boutron I, Altman DG, Hopewell S, Vera-Badillo F, Tannock I, Ravaud P. Impact of spin in the abstracts of articles reporting results of randomized controlled trials in the field of cancer: the SPIIN randomized controlled trial. J Clin Oncol. 2014;32:4120-6. doi:10.1200/jco.2014.56.7503.

61. Lieb K, von der Osten-Sacken J, Stoffers-Winterling J, Reiss N, Barth J. Conflicts of interest and spin in reviews of psychological therapies: a systematic review. BMJ Open. 2016;6:e010606. doi:10.1136/bmjopen-2015-010606.

62. Yavchitz A, Ravaud P, Altman DG, Moher D, Hróbjartsson A, Lasserson T, et al. A new classification of spin in systematic reviews and meta-analyses was developed and ranked according to the severity. J Clin Epidemiol. 2016;75: 56-65. doi:10.1016/j.jclinepi.2016.01.020.

63. European Agency for the Evaluation of Medicinal Products, Committee for Proprietary Medicinal Products. Points to consider on multiplicity issues in clinical trials. CPMP/EWP/908/99. 19 Sep 2002. http://www.ema.europa.eu/ docs/en_GB/document_library/Scientific_guideline/2009/09/WC500003640. pdf. Accessed 11 Mar 2017.

64. Sun X, Briel M, Busse JW, You JJ, Akl EA, Mejza F, et al. Credibility of claims of subgroup effects in randomised controlled trials: systematic review. BMJ. 2012;344:e1553. doi:10.1136/bmj.e1553.

65. Williamson PR, Altman DG, Blazeby JM, Clarke M, Devane D, Gargon E, et al. Developing core outcome sets for clinical trials: issues to consider. Trials. 2012:13:132. doi:10.1186/1745-6215-13-132.

66. Tugwell P, Boers M, Brooks P, Simon L, Strand V, Idzerda L. OMERACT: an international initiative to improve outcome measurement in rheumatology. Trials. 2007;8:38. doi:10.1186/1745-6215-8-38

67. Williamson P. The COMET Initiative [abstract]. Trials. 2013;14 Suppl 1:065. doi:10.1186/1745-6215-14-s1-065

68. Gargon E, Williamson PR, Altman DG, Blazeby JM, Clarke M. The COMET Initiative database: progress and activities update (2014). Trials. 2015;16:515. doi:10.1186/s13063-015-1038-x.

69. Grading of Recommendations Assessment, Development and Evaluation (GRADE). http://www.gradeworkinggroup.org/. Accessed 11 Mar 2017.

70. Kelly S, Lafortune L, Hart N, Cowan K, Fenton M. Brayne C; Dementia Priority Setting Partnership. Dementia priority setting partnership with the James Lind Alliance: using patient and public involvement and the evidence base to inform the research agenda. Age Ageing. 2015;44:985-93. doi:10.1093/ ageing/afv143. 